\title{
Predictive Power of Preoperative Serum Total Bilirubin for the Outcomes Following Pancreaticoduodenectomy
}

\author{
Sara Saeidi Shahri (ii) ${ }^{1}$, Mohsen Aliakbarian (iD ${ }^{1,2,{ }^{*}}$ and Lida Jarahi ${ }^{3}{ }^{3}$ \\ ${ }^{1}$ Surgical Oncology Research Center, Mashhad University of Medical Sciences, Mashhad, Iran \\ ${ }^{2}$ Department of General Surgery, Imam Reza Hospital, Mashhad, Iran \\ ${ }^{3}$ Department of Community Medicine, Faculty of Medicine, Mashhad University of Medical Sciences, Mashhad, Iran \\ "Corresponding author: Department of General Surgery, Imam Reza Hospital, Mashhad, Iran. Tel: +98-9155111367, Email: aliakbarianm@mums.ac.ir
}

Received 2020 February 29; Revised 2020 October 06; Accepted 2020 October 10.

\begin{abstract}
Background: The high levels of bilirubin in patients with periampullary cancers may increase the morbidity or mortality after curative surgery.

Objectives: We aimed at evaluating the predictive power of preoperative serum total bilirubin for the outcomes after pancreaticoduodenectomy (PD) in resectable periampullary cancers.

Methods: The data of 80 patients, who had undergone PD, were retrospectively analyzed. Regarding the preoperative bilirubin, we opted for $20 \mathrm{mg} / \mathrm{dL}$ as the cut-off value to divide patients into two groups to be subjected to simple and multiple logistic regression. Results: A total of 80 patients with a mean age of $54.90 \pm 14.33$ years underwent PD. The median preoperative bilirubin level was 4.7 $\mathrm{mg} / \mathrm{dL}$ and the majority of cases $(88.8 \%)$ had bilirubin $<20 \mathrm{mg} / \mathrm{dL}$. While there was no significant difference in the mortality between bilirubin groups $(\mathrm{P}=0.266)$, bilirubin $\geq 20 \mathrm{mg} / \mathrm{dL}$ remarkably increased the postoperative morbidity $(\mathrm{P}=0.012$, Odds ratio $=3.04)$; $57.5 \%$ of cases underwent biliary drainage before surgery, which did not impact the mortality and morbidity. Multiple analysis by a logistic regression model disclosed that the only statistically significant variable for mortality was the total operative time $(\mathrm{P}=$ 0.038) and among all factors, total bilirubin level was the only independent predictor for the morbidity status $(\mathrm{P}=0.009)$.

Conclusions: This study suggested that preoperative biliary drainage should only be limited to patients with high bilirubin levels $(\geq 20 \mathrm{mg} / \mathrm{dL}$ ) or expected delayed surgeries.
\end{abstract}

Keywords: Bilirubin, Pancreaticoduodenectomy, Pancreatic Cancer, Mortality, Morbidity, Surgical Oncology

\section{Background}

Obstructive jaundice is known as the most common presentation in patients with periampullary tumors. Relieving jaundice is assumed to be accompanied by more favorable postoperative outcomes since progressive high bilirubin levels are associated with the pro-inflammatory state resulting from the portal and systemic endotoxemia, as well as bacterial translocation, which may lead to inducing an uncontrolled inflammatory cascade developing complications (1-3).

Since surgery in patients with jaundice has been considered accompanied by the increased rate of mortality and morbidity, preoperative biliary drainage (PBD) was introduced to improve the outcomes following surgery $(4,5)$.

Primarily studies have suggested that PBD in patients with obstructive jaundice decreased the rate of postoperative mortality and complications. However, in recent in- vestigations, there has been no significant relationship between biliary drainage and mortality rate (5-9).

Contamination of bile may occur after biliary drainage, especially when a stent is placed. In a long period of stenting (more than 4 weeks), an extensive inflammatory reaction to foreign bodies occur in the biliary tract that provides a suitable condition for bacterial colonization in the biliary tree leading to stent occlusion and eventually, a great risk for anastomosis leakage after surgery. However, the quality of drainage, duration, and method of drainage is implicated (10).

In recent years, several studies have suggested that not only will PBD decrease mortality and morbidity rates, but it could also be harmful in some cases since there would be worries about drainage-induced complications, increased positive intraoperative biliary cultures, and postoperative infections (11). 


\section{Objectives}

This retrospective study aimed at evaluating the predictive power of preoperative bilirubin for the outcomes of patients with periampullary tumors undergoing pancreaticoduodenectomy (PD), as well as the effect of PBD on postoperative outcomes.

\section{Methods}

\subsection{Study Design}

This observational retrospective study was conducted on admitted patients with a confirmed diagnosis of periampullary tumors, who had undergone PD at the Department of Surgery of Imam Reza Hospital, Mashhad University of Medical Sciences in the recent 4 years from March 2013 to March 2017. The study was approved by the ethics committee of Mashhad University of Medical Sciences (code: IR.MUMS.fm.REC.1396.446).

As a matter of routine, periampullary tumors are primarily diagnosed by clinical and radiological manifestations. Surgery was performed on patients, whose clinical and radiological symptoms matched those of the periampullary cancers and the diagnosis was confirmed with specimen postoperatively. Sampling was performed in cases, where there was a diagnostic ambiguity or those borderline resectable cases candidate for neoadjuvant treatment.

Patients who underwent palliative surgeries as well as those whose data were incomplete were excluded. In total, 110 patients underwent PD (international classification of diseases [ICD]-9, 52.6), and 80 cases were included in this study.

All medical records of the cases, including demographic data, medical history, preoperative variables such as biliary drainage and instrumentation, type and stage of the tumor (based on the pathology reports), total and direct serum bilirubin levels (within 1 week from the operation), and liver function tests, were extracted and analyzed.

Intraoperative variables, including the type of procedure, total operative time in addition to postoperative complications such as surgical site infection, hemorrhage, pancreatic fistula, ascites, intra-abdominal abscess, deep vein thrombosis (DVT), and pulmonary emboli, were also reviewed and analyzed. The duration of hospital stay and intensive care unit (ICU) stay, as well as the need for relaparotomy and re-admission, were collected as well.

Preoperative biliary instrumentation was defined as the nonsurgical insertion of the cannula in the biliary tract by either endoscopic retrograde cholangiopancreatography (ERCP) or percutaneous transhepatic cholangiography (PTC).

Early mortality was defined as any death noted within 30 days postoperatively or upon primary admission. Early morbidity was described as one or more postoperative complications within 30 days from the operation or before discharge from the hospital.

In previous studies (12-14), "preoperative serum total bilirubin" has been widely used as an appropriate variable in determining prognosis in these patients.

Regarding the serum total bilirubin levels, based on the credible research done by Billingsley et al. (12), we used the cut-off value of $20 \mathrm{mg} / \mathrm{dL}$ to divide patients into two groups to be subjected to logistic regression analysis.

\subsection{Patients' Follow-Up}

All "perioperative" medical records of cases were extracted and analyzed by reviewing hospital documents; to register 30-day mortality and morbidities and readmission, patients were followed-up by referring to surgical clinics. Some patients were followed by phone calls.

\subsection{Statistical Analysis}

For statistical analysis, we used IBM SPSS 21. Continuous variables were expressed as means \pm standard deviation (SD) or medians and interquartile ranges (IQRs) when applicable. The relationship among categorical variables was performed by Pearson Chi-square analysis and Fisher's exact test. Also, either an independent sample $t$-test or Mann-Whitney test was applied for continuous variables.

If multiple variables were confirmed to be statistically significant by the simple analysis, then, we would apply a binary logistic regression model for multiple analyses of all factors. Significance was considered at the probability level of 0.05 .

Receiver operating characteristics (ROC) analysis of preoperative bilirubin was performed to determine the optimal cut-off value for predicting postoperative mortality.

\section{Results}

In our primary assessment, 110 cases were admitted with the confirmed diagnosis of periampullary tumors and undergoing surgery from March 2013 to March 2017 in 4 years. Of them, 5 cases underwent total pancreatectomy, and 10 patients had palliative surgeries as a result of being identified as having unresectable tumors; also, preoperative data were not available for 15 patients, who were 
excluded from the study. A total of 80 patients were included. The demographic and clinical characteristics of 80 patients are shown in Table 1.

The mean $\pm \mathrm{SD}$ (min-max) age of the patients was 54.90 \pm 14.33 years (22-82), 40 (50\%) of whom were male and 40 (50\%) were female. We divided patients into 3 groups regarding their ages; $60 \%$ of all cases had the age range of 40 to 65 years, $16.2 \%$ were younger than 40 years old, and $23.8 \%$ were older than 65 years old. The majority of patients (61.3\%) had jaundice as the presenting symptom at the time of admission. Although presenting jaundice on admission did not impact the postoperative outcomes, jaundiced patients had a significantly higher probability to develop wound infection after surgery $(\mathrm{P}=0.047)$.

Based on the pathology reports, the prominent diagnosed tumor was cancer of the head of the pancreas in 40 patients (50\%) and ampullary tumors with an incidence rate of 30\% (24/80) occupied the second position. According to the American Joint Committee on Cancer (AJCC) TNM staging system, the major number of the patients (32.5\%) had the tumor in stage IIB followed by stage IB with a rate of $27.5 \%$. The median preoperative Aspartate Aminotransferase (AST) level was $63 \mathrm{IU} / \mathrm{L}(13$ - $483 \mathrm{IU} / \mathrm{L})$, and the median alanine aminotransferase (ALT) level was 69 IU/L (9 $570 \mathrm{IU} / \mathrm{L})$.

The type of operation performed was classified into pylorus-preserving PD in 49 (61.2\%) patients and classic PD in $38.8 \%$ of cases. There was no significant association between the type of procedure and postoperative mortality and complications.

On univariate analysis, none of the age, sex, comorbidities, preoperative liver function tests, pathological type and stage of tumors, and type of procedure had a statistically significant effect on the morbidity and mortality status (Table 2).

The median total operative time was 420 minutes (270 $630 \mathrm{~min})$, which significantly affected the mortality status $(\mathrm{P}=0.033)$.

Totally, $88.7 \%$ (71/80) of all patients recovered and $11.3 \%$ (9/80) died within 30 days of the operation due to surgical and cardiac complications. A detailed description of the mortality is summarized in Table 3.

The overall postoperative morbidity was $37.5 \%$. The main postoperative complication occurred was wound infection in $25 \%$ of patients (20/80) followed by intraabdominal collection in $7.5 \%$ (6/80) and hemorrhage in $6.3 \%$ (5/80). Among all major complications, only the hemorrhage significantly correlated with postoperative mortality $(\mathrm{P}=0.009$, Table 3$)$.

The median length of hospital stay was 12 days (3 49 days) and was significantly increased by the develop- ment of complications and undergoing re-laparotomy (P $=0.003,0.020$, respectively). Although the duration of ICU admittance was slightly longer in patients with total bilirubin $\geq 20 \mathrm{mg} / \mathrm{dL}$, both ICU and total hospital stay were not affected by total bilirubin levels $(\mathrm{P}=0.145,0.400$, respectively).

A total of $7(8.8 \%)$ cases required postoperative exploratory laparotomy due to complications, which notably correlated with the mortality rate $(\mathrm{P}=0.028)$.

In this study, median serum total bilirubin level was $4.70 \mathrm{mg} / \mathrm{dL}$ (0.30 - $33.20 \mathrm{mg} / \mathrm{dL})$ and median direct bilirubin level was $2.90 \mathrm{mg} / \mathrm{dL}$ (0.10 - $24.10 \mathrm{mg} / \mathrm{dL})$. On univariate analysis, total bilirubin levels had no significant relationship with the mortality status $(\mathrm{P}=0.283)$, but it remarkably impacted the morbidity status $(\mathrm{P}=0.003)$.

Preoperative total bilirubin levels were categorized into two groups with a cut-off value of $20 \mathrm{mg} / \mathrm{dL}$. The majority of cases (88.8\%) had a total bilirubin of less than 20 $\mathrm{mg} / \mathrm{dL}$. Although there was a tendency for the rate of mortality to be slightly higher in patients with bilirubin $\geq$ $20 \mathrm{mg} / \mathrm{dL}$ (22\% vs. 9\% for the group with bilirubin $<20$ $\mathrm{mg} / \mathrm{dL})$, no significant correlation was observed between these two bilirubin groups and 30-day mortality status ( $\mathrm{P}$ $=0.266$ ); however, bilirubin $\geq 20 \mathrm{mg} / \mathrm{dL}$ significantly increased morbidity following PD by almost 3 times ( $\mathrm{P}=$ 0.012 , Odd ratio $=3.04,95 \%$ CI 0.887 to 10.438 ).

Multiple analysis of potential variables in association with the postoperative mortality and morbidity status by a logistic regression model disclosed that the only statistically significant variable for mortality was the total operative time $(\mathrm{P}=0.038)$ and among all factors, total bilirubin level was the only independent predictor for the morbidity status $(\mathrm{P}=0.009)$ (Table 4$)$.

A total of 46 (57.5\%) patients had a history of PBD; 43 patients underwent ERCP with the biliary tract instrumentation before surgery and only 3 cases (6.5\%) had a history of preoperative percutaneous biliary drainage with PTC. Postoperative mortality and morbidity status were not significantly different in patients, who underwent PBD and patients with early surgery without drainage $(P=0.999$, 0.304 , respectively). Also, the method of PBD (endoscopic vs. percutaneous) did not affect the outcomes following PD $(\mathrm{P}>0.05)$.

The ROC analysis of preoperative bilirubin was performed to determine the optimal cut-off value of preoperative serum bilirubin for predicting postoperative mortality. The area under the ROC curve for predicting mortality and the optimal cut-off value of preoperative bilirubin level was $0.5994 \mathrm{mg} / \mathrm{dL}$ and $5.15 \mathrm{mg} / \mathrm{dL}$, respectively(Figure 1). 
Table 1. Clinical and Demographic Characteristics and Associated Postoperative Mortality Status

\begin{tabular}{|c|c|c|c|}
\hline \multirow[t]{2}{*}{ Characteristics } & \multirow{2}{*}{ No. (\%) } & \multicolumn{2}{|c|}{ Postoperative Mortality } \\
\hline & & No. (\%) & PValue \\
\hline Sex & & & 0.999 \\
\hline Male & $40(50)$ & $4(44.4)$ & \\
\hline Female & $40(50)$ & $5(55.6)$ & \\
\hline Age groups, y & & & 0.301 \\
\hline$<40$ & $13(16.2)$ & $1(11.1)$ & \\
\hline $40-65$ & $48(60)$ & $4(44.4)$ & \\
\hline$\geq 65$ & $19(23.8)$ & $4(44.4)$ & \\
\hline Jaundice & $49(61.3)$ & $6(66.7)$ & 0.999 \\
\hline Medical history & & & 0.437 \\
\hline No history & $61(76.3)$ & $6(66.7)$ & \\
\hline DM & $4(5)$ & $0(0)$ & \\
\hline HTN & $8(10)$ & $1(11.1)$ & \\
\hline CAD & $3(3.8)$ & $1(11.1)$ & \\
\hline $\mathrm{DM}+\mathrm{HTN}+\mathrm{CAD}$ & $4(5)$ & $1(11.1)$ & \\
\hline Type of tumor & & & 0.348 \\
\hline Pancreatic & $40(50)$ & $6(66.7)$ & \\
\hline Ampullary & $24(30)$ & $1(11.1)$ & \\
\hline Duodenal & $10(12.5)$ & $2(22.2)$ & \\
\hline Biliary & $6(7.5)$ & $0(0)$ & \\
\hline Stage of tumor & & & 0.120 \\
\hline 0 & $7(8.8)$ & $0(0)$ & \\
\hline $1 \mathrm{~A}$ & $13(16.3)$ & $1(11.1)$ & \\
\hline $1 \mathrm{~B}$ & $22(27.5)$ & $1(11.1)$ & \\
\hline IIA & $7(8.8)$ & $0(0)$ & \\
\hline IIB & $26(32.5)$ & $5(55.6)$ & \\
\hline III & $5(6.3)$ & $2(22.2)$ & \\
\hline Preoperative biliary drainage & $46(57.5)$ & $6(66.7)$ & 0.726 \\
\hline Type of drainage $(n=46)$ & & & 0.433 \\
\hline Endoscopic & $43(93.5)$ & $5(55.6)$ & \\
\hline Percutaneous & $3(6.5)$ & $1(11.1)$ & \\
\hline \multicolumn{4}{|l|}{ Type of PD } \\
\hline Pylorus preserving PD & $49(61.2)$ & $6(66.7)$ & 0.999 \\
\hline Classic PD & $31(38.8)$ & $3(33.3)$ & \\
\hline Morbidity & $30(37.5)$ & $8(88.9)$ & 0.001 \\
\hline \multicolumn{4}{|l|}{ Postoperative complications $(\mathrm{n}=\mathbf{3 0}$ ) } \\
\hline Pancreatic fistula & $2(2.5)$ & $0(0)$ & \\
\hline Hemorrhage & $5(6.3)$ & $3(33.3)$ & \\
\hline Ascites & $3(3.8)$ & $1(11.1)$ & \\
\hline Intra-abdominal abscess & $6(7.5)$ & $2(22.2)$ & \\
\hline Wound infection & $20(25)$ & $4(44.4)$ & \\
\hline DVT & $1(1.3)$ & $0(0)$ & \\
\hline Pulmonary emboli & $2(2.5)$ & $0(0)$ & \\
\hline Re-laparotomy & $7(8.8)$ & $3(33.3)$ & 0.028 \\
\hline Re-admission & $19(23.8)$ & $2(22.2)$ & 0.999 \\
\hline Preoperative total bilirubin, $\mathrm{mg} / \mathrm{dL}$ & & & 0.266 \\
\hline$<20$ & $71(88.8)$ & $2(22.2)$ & \\
\hline$\geq 20$ & $9(11.2)$ & $7(77.8)$ & \\
\hline
\end{tabular}

Abbreviations: CAD, cardiovascular disease; DM, diabetes mellitus; DVT, deep vein thrombosis; HTN, hypertension; PD, pancreaticoduodenectomy. 


\begin{tabular}{|c|c|c|c|c|}
\hline Characteristics & Range & Live Patients & Died Patients & PValue \\
\hline Age, $y$ & $22-82$ & $54.94 \pm 14.53$ & $54.56 \pm 13.41$ & 0.940 \\
\hline Preoperative AST, IU/L & $13-483$ & $61.5(74)$ & $138(185)$ & 0.110 \\
\hline Preoperative ALT, IU/L & $9-570$ & $68(87)$ & $79(160)$ & 0.517 \\
\hline Preoperative total bilirubin, $\mathrm{mg} / \mathrm{dL}$ & $0.3-33.2$ & $4.4(9.3)$ & $7.46(17.7)$ & 0.283 \\
\hline Preoperative direct bilirubin, $\mathrm{mg} / \mathrm{dL}$ & $0.1-24.1$ & $2.9(6.9)$ & $4.1(11.13)$ & 0.248 \\
\hline Total operative time, $\mathrm{min}$ & $270-630$ & $381.11 \pm 56.44$ & $432.04 \pm 66.73$ & 0.033 \\
\hline Length of ICU stay, d & $1-12$ & $1(1)$ & $2(7)$ & 0.065 \\
\hline Length of hospital stay, d & $3-49$ & $11(9)$ & $17(14)$ & 0.691 \\
\hline
\end{tabular}

Abbreviations: ALT, alanine transaminase; AST, aspartate transaminase; IQR: interquartile range; SD, standard deviation.

${ }^{\mathrm{a}}$ Values are expressed as mean $\pm \mathrm{SD}$ or median (IQR).

\begin{tabular}{|c|c|c|c|}
\hline & Bilirubin $<20, \mathrm{mg} / \mathrm{dL}$ & Bilirubin $\geq 20, \mathrm{mg} / \mathrm{dL}$ & P Value \\
\hline Operative time, $\min$ & $420(270-630)$ & $420(390-480)$ & 0.972 \\
\hline Overall postoperative morbidity & $23(28.8)$ & $7(8.8)$ & 0.012 \\
\hline Pancreatic fistula & $2(2.5)$ & $0(0)$ & 0.999 \\
\hline Ascites & $2(2.5)$ & $1(1.2)$ & 0.304 \\
\hline Intraabdominal & $5(6.2)$ & $1(1.2)$ & 0.523 \\
\hline Abscess & $16(20)$ & $4(5)$ & 0.217 \\
\hline Wound infection & $1(1.2)$ & $0(0)$ & 0.999 \\
\hline Deep vein thrombosis & $2(2.5)$ & $0(0)$ & 0.999 \\
\hline \multicolumn{4}{|l|}{ Pulmonary emboli } \\
\hline Length of ICU admittance, $d$ & $1(1-12)$ & $2(1-11)$ & 0.145 \\
\hline Hospital stay, d & $11(3-49)$ & $14(8-30)$ & 0.400 \\
\hline Postoperative deaths & $7(7.8)$ & $2(2.5)$ & 0.266 \\
\hline Re-laparotomy & $6(7.5)$ & $1(1.2)$ & 0.581 \\
\hline Re-admission & $16(20)$ & $3(3.8)$ & 0.437 \\
\hline
\end{tabular}

${ }^{\mathrm{a}}$ Values are expressed as No. (\%) or median (range).

\section{Discussion}

In recent decades, the curative and palliative effects of PBD for periampullary tumors have been discussed. One of the large prospective randomized clinical studies was performed by Pitt et al. (15) on 79 consecutive cases of obstructive jaundice. It was performed to assess the effect of preoperative percutaneous trans-hepatic biliary drainage (PTBD) on the outcomes of surgery. Although the mortality and morbidity rates were not significantly different in the PTBD group, the length of hospital stay was longer. The prolonged hospitalization produced higher costs for patients. Therefore, investigators concluded that not only preoper- ative PTD reduce mortality and complications, but it may also increase in-patient costs and should not be administered routinely.

By retrospectively looking at 285 cases with or without jaundice, undergoing Whipple surgery for benign and malignant pancreatic tumors, Trede and Schwall (16) stated that regardless of the severity of jaundice, postoperative mortality and morbidity were considerably lower in patients with PBD.

Although in the present study the overall postoperative morbidity and mortality status was not significantly different in jaundiced patients, they were more likely to develop wound infection after surgery. 


\begin{tabular}{|c|c|c|c|c|c|c|}
\hline \multirow{2}{*}{ Variables } & \multirow{2}{*}{ B } & \multirow{2}{*}{ Standard Error } & \multirow{2}{*}{ PValue } & \multirow{2}{*}{ Odds Ratio } & \multicolumn{2}{|c|}{ 95\% Confidence Interval } \\
\hline & & & & & Lower & Upper \\
\hline Age & -0.018 & 0.030 & 0.559 & 0.982 & 0.926 & 1.043 \\
\hline \multicolumn{7}{|l|}{ Sex } \\
\hline Male & -0.727 & 0.813 & 0.371 & 0.483 & 0.098 & 2.380 \\
\hline \multicolumn{7}{|l|}{ Comorbidities } \\
\hline Yes & Referent & & & & & \\
\hline No & -0.797 & 0.842 & 0.344 & 0.451 & 0.087 & 2.349 \\
\hline \multicolumn{7}{|l|}{ Tumor origin } \\
\hline Duodenum & -1.477 & 1.368 & 0.280 & 0.228 & 0.016 & 3.336 \\
\hline Ampulla of Vater & -2.351 & 1.797 & 0.191 & 0.095 & 0.003 & 3.227 \\
\hline Common bile duct & -1.780 & 1.467 & 0.255 & 0.169 & 0.010 & 2.990 \\
\hline \multicolumn{7}{|l|}{ Staging } \\
\hline IA & Referent & & & & & \\
\hline IB & 0.661 & 1.797 & 0.713 & 1.936 & 0.057 & 65.578 \\
\hline IIA & -0.322 & 1.522 & 0.832 & 0.725 & 0.037 & 14.316 \\
\hline IIB & 2.510 & 2.044 & 0.219 & 12.311 & 0.224 & 676.461 \\
\hline III & 2.228 & 1.406 & 0.113 & 9.282 & 0.590 & 146.068 \\
\hline 0 & 0.554 & 1.935 & 0.775 & 1.740 & 0.039 & 77.204 \\
\hline \multicolumn{7}{|l|}{$\begin{array}{l}\text { Preoperative biliary } \\
\text { drainage }\end{array}$} \\
\hline Yes & Referent & & & & & \\
\hline No & -0.188 & 0.791 & 0.813 & 0.829 & 0.176 & 3.910 \\
\hline \multicolumn{7}{|l|}{ Type of Whipple } \\
\hline Pylorus Preserving & Referent & & & & & \\
\hline Classic & 1.216 & 1.190 & 0.307 & 3.374 & 0.327 & 34.770 \\
\hline Operative time & -0.003 & 0.006 & 0.629 & 0.997 & 0.985 & 1.009 \\
\hline ALT & 0.010 & 0.007 & 0.164 & 1.010 & 0.996 & 1.024 \\
\hline AST & -0.004 & 0.008 & 0.615 & 0.996 & 0.981 & 1.011 \\
\hline $\begin{array}{l}\text { Preoperative total } \\
\text { bilirubin }\end{array}$ & 0.149 & 0.057 & 0.009 & 1.161 & 1.038 & 1.299 \\
\hline
\end{tabular}

${ }^{\mathrm{a}}$ Early morbidity was described as one or more postoperative complications within 30 days from the operation or before discharge from the hospital.

The high levels of preoperative serum bilirubin should not be considered the only proper indication for PBD, since drainage may interrupt the postoperative course with infections resulting in higher morbidity.

Previous studies have shown that serum bilirubin $\geq$ $10 \mathrm{mg} / \mathrm{dL}$ is an apparent risk factor for postoperative complications $(17,18)$. In an investigation conducted by Lai et al. (7), no considerable differences were found in mortality and morbidity status between patients with bilirubin 6.20 $\mathrm{mg} / \mathrm{dL}$ to $11.50 \mathrm{mg} / \mathrm{dL}$ and those with bilirubin $13 \mathrm{mg} / \mathrm{dL}$ to $18 \mathrm{mg} / \mathrm{dL}$.

A study carried out from 2004 to 2009 by Sauvanet et al. (19) on 1200 patients, who underwent PD, suggests that obstructive jaundice was associated with an increase in postoperative morbidity and a decrease in the rate of long-term survival.

In a 10-year analysis in 123 veterans affairs' medical centers from 1990 to 2000 by Billingsley et al. (12) on the out- 


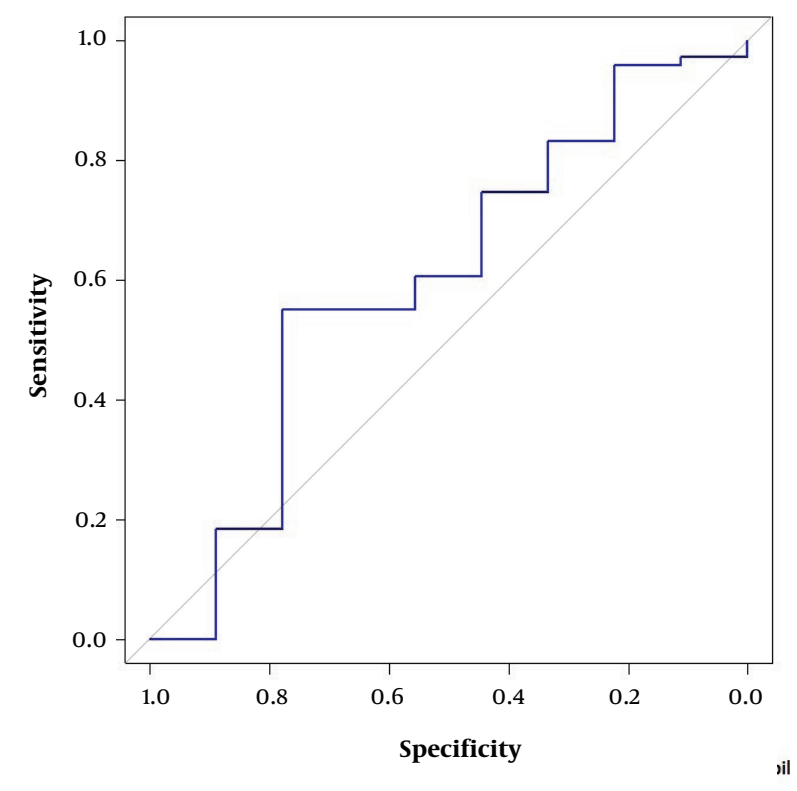

Figure 1. Reciever operating characteristics (ROC) analysis of preoperative total bilirubin

comes following Whipple procedure, the preoperative total bilirubin level was shown to be one of the significant predictors for postoperative outcomes in a way that levels higher than $20 \mathrm{mg} / \mathrm{dL}$ effectively increased 30-day postoperative mortality.

In the present study, we primarily opted for $20 \mathrm{mg} / \mathrm{dL}$ as a cut-off value to divide patients according to their total serum bilirubin levels. However, there was a tendency for postoperative mortality to be higher in patients with preoperative bilirubin $\geq 20 \mathrm{mg} / \mathrm{dL}$ (22\% vs. $9 \%$ for the group with bilirubin $<20 \mathrm{mg} / \mathrm{dL}$ ), the relationship was not statistically significant. In contrast, in both univariate and multivariate analyses, preoperative serum bilirubin was observed to be the only independent variable affecting 30day postoperative morbidity status. The risk of a complicated postoperative course was 3 times higher for patients, whose bilirubin was $\geq 20 \mathrm{mg} / \mathrm{dL}$.

Since this cut-off value could not predict postoperative mortality in our study, we attempted to determine an optimal cut-off value based on the preoperative bilirubin levels of our patients for predicting mortality status. Regarding this investigation, the area under the ROC curve was 0.6, and $5.15 \mathrm{mg} / \mathrm{dL}$ was set to be the optimal value for serum bilirubin with $55 \%$ sensitivity and $78 \%$ specificity. This cutoff value could not predict the mortality accurately since the area under the ROC curve represents that "preoperative bilirubin" may be a "poor test" for predicting mortality.

The impacts of percutaneous and endoscopic drainage on the restoration of the enterohepatic cycle are different. Currently, ERCP as a less invasive procedure is preferable to PTC. Percutaneous drainage is usually reserved when endoscopic is not successful.

In our investigation, the prominent method of drainage was endoscopic via ERCP in $96.7 \%$ of all patients undergoing PBD. There was no considerable difference in overall postoperative mortality and morbidity status between patients who underwent PBD (endoscopic or percutaneous) and patients with early surgery without PBD. Based on the findings, undergoing biliary drainage before operation did not impact the postoperative outcomes; however, it might have delayed the curative surgery.

In several analyses, PBD either endoscopic or percutaneous was not found beneficial for the outcome improvement of surgery, but significantly prolonged hospitalization and consequently increased costs $(9,15)$.

In the recent systematic review of Cochrane database (20) of 6 randomized trials including 4 studies on percutaneous drainage and 2 studies on endoscopic stenting and sphincterotomy as a method of PBD, however, the overall mortality did not differ between drainage groups and early surgery group; the serious morbidity and hospitalization were exceeded in the patients undergoing drainage.

In Iran, patients with periampullary malignancies usually are visited by general practitioners or internists for the first time, and most often diagnostic less-invasive methods such as MRI or MRCP are not available. There also may take a considerable amount of time for referring patients to an experienced surgical center, where they can undergo PD; consequently, the majority of the patients undergoing PD may receive biliary drainage before surgery.

Early ERCP, not only as a precious available diagnostic mode but also a palliative and therapeutic modality for the prevention of cholangitis or other obstructive jaundicerelated complications, has been recommended.

By considering drainage-induced complications and surgery delays, routine biliary drainage may be disadvantageous; however, PBD should be taken into account for those patients requiring further diagnostic evaluations before surgery or staying on a long surgical waiting list or in the occasion of any delay that is inevitable in their disease courses.

Based on the findings, we adopted an algorithm for the medical approach to surgical candidates of periampullary tumors, by considering preoperative bilirubin levels and other conditions causing delays in surgery as factors determining whether they need to undergo biliary drainage before surgery (Figure 2). 


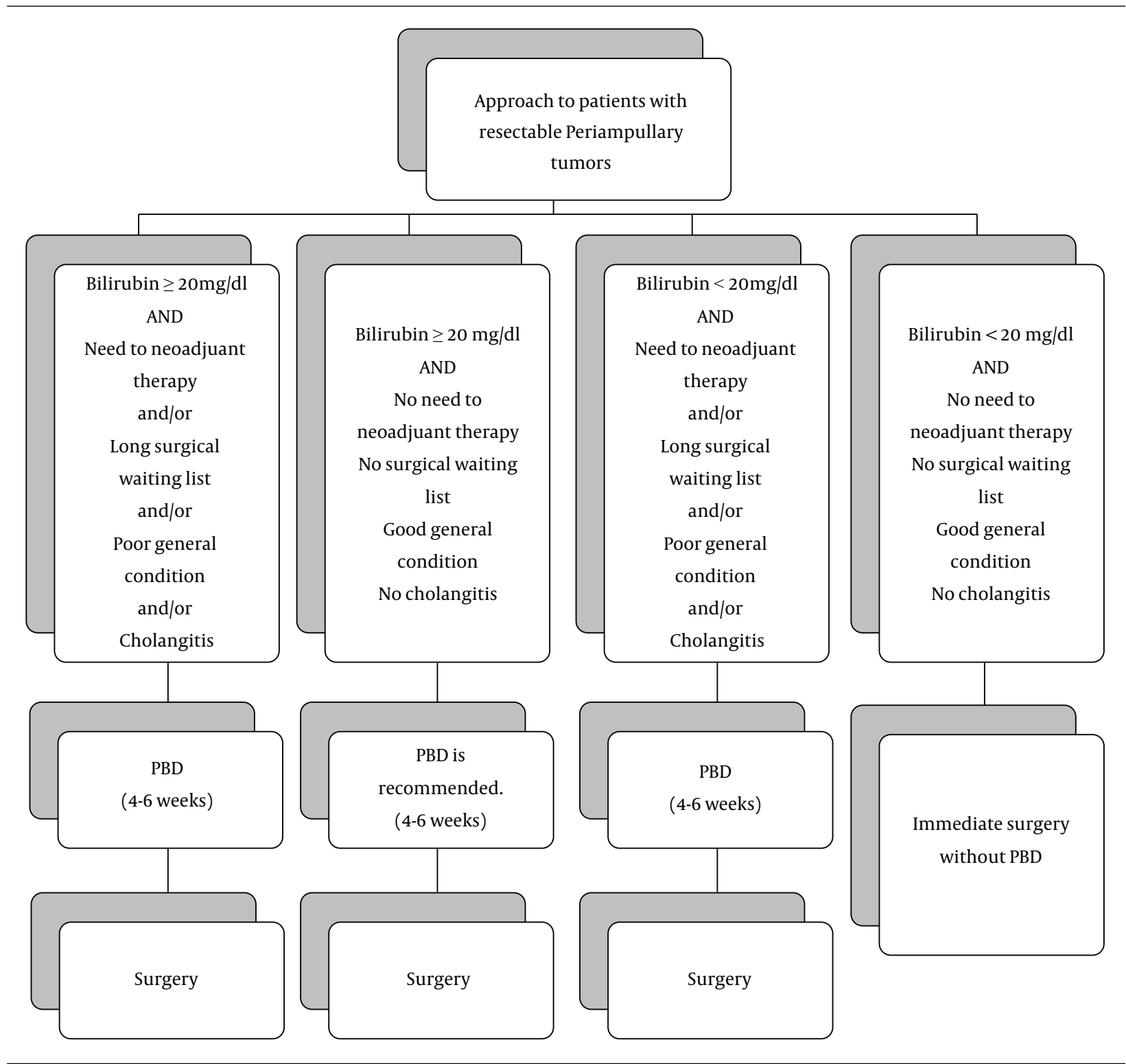

Figure 2. Algorithm of approach to resectable periampullary tumors based on total bilirubin

The present study was conducted retrospectively, and it may be limited in the description of details. Also, all PDs were performed in the same institution; on the contrary, multicenter prospective studies are more advantageous.

However, our surgical ward as a high-volume surgical center with annually 30 cases of periampullary tumors referring to, undergoing PD in the east of Iran, provided adequate sample size to be subjected for credible statistical analysis; also, including patients operated on by the same surgical team eliminates biases.

\subsection{Conclusions}

This study suggested that the PBD should not be part of the routine medical approach to surgical candidates of periampullary tumors, unless in cases with high bilirubin levels ( $\geq 20 \mathrm{mg} / \mathrm{dL}$ ) or expected delayed surgeries.

\section{Acknowledgments}

The results of this study formed a part of the graduate thesis submitted by the first author for the doctorate degree in medicine (Doctor of Medicine). 


\section{Footnotes}

Authors' Contribution: Sara Saeidi Shahri participated in design of the study, data collection, statistical analysis, and drafting of the manuscript. Mohsen Aliakbarian participated in the main idea, design of the study and supervision, and provided oversight when the manuscript was being drafted. Lida Jarahi contributed to the statistical analysis and interpretation of the data.

Conflict of Interests: The authors declare no competing interests.

Ethical Approval: The ethical approval code was IR.MUMS.fm.REC.1396.446.

Funding/Support: We did not have any funding source for conducting this investigation.

\section{References}

1. Bemelmans MH, Gouma DJ, Greve JW, Buurman WA. Cytokines tumor necrosis factor and interleukin-6 in experimental biliary obstruction in mice. Hepatology. 1992;15(6):1132-6. doi: 10.1002/hep.1840150626. [PubMed: 1592352].

2. Nehez L, Andersson R. Compromise of immune function in obstructive jaundice. Eur J Surg. 2002;168(6):315-28. doi: 10.1080/11024150260284815. [PubMed: 12428868].

3. Sewnath ME, van der Poll T, van Noorden CJ, ten Kate FJ, Gouma DJ. Cholestatic interleukin-6-deficient mice succumb to endotoxininduced liver injury and pulmonary inflammation. Am J Respir Crit Care Med. 2004;169(3):413-20. doi: 10.1164/rccm.200303-311OC. [PubMed: 14604838].

4. Kawarada Y, Higashiguchi T, Yokoi H, Vaidya P, Mizumoto R. Preoperative biliary drainage in obstructive jaundice. Hepato Gastroenterol. 1995;42(4):300.

5. van der Gaag NA, Rauws EA, van Eijck $\mathrm{CH}$, Bruno MJ, van der Harst E, Kubben FJ, et al. Preoperative biliary drainage for cancer of the head of the pancreas. NEngl JMed. 2010;362(2):129-37. doi:10.1056/NEJMoa0903230. [PubMed: 20071702].

6. Denning DA, Ellison EC, Carey LC. Preoperative percutaneous transhepatic biliary decompression lowers operative morbidity in patients with obstructive jaundice. Am J Surg. 1981;141(1):61-5. doi: 10.1016/0002-9610(81)90013-1. [PubMed: 6779653].

7. Lai EC, Mok FP, Fan ST, Lo CM, Chu KM, Liu CL, et al. Preoperative endoscopic drainage for malignant obstructive jaundice. Br J Surg. 1994;81(8):1195-8. doi:10.1002/bjs.1800810839. [PubMed: 7741850].

8. Sewnath ME, Karsten TM, Prins MH, Rauws EJ, Obertop H, Gouma DJ. A meta-analysis on the efficacy of preoperative biliary drainage for tumors causing obstructive jaundice. Ann Surg. 2002;236(1):17-27. doi: 10.1097/00000658-200207000-00005. [PubMed: 12131081]. [PubMed Central: PMC1422544].
9. Wang Q, Gurusamy KS, Lin H, Xie X, Wang C, Wang C. Preoperative biliary drainage for obstructive jaundice. Cochrane Database of Systematic Reviews. 2008. doi: 10.1002/14651858.CD005444.pub2.

10. Povoski SP, Karpeh MJ, Conlon KC, Blumgart LH, Brennan MF. Association of preoperative biliary drainage with postoperative outcome following pancreaticoduodenectomy. Ann Surg. 1999;230(2):131-42. doi: 10.1097/00000658-199908000-00001. [PubMed: 10450725]. [PubMed Central: PMC1420854].

11. Lai EC, Lau SH, Lau WY. The current status of preoperative biliary drainage for patients who receive pancreaticoduodenectomy for periampullary carcinoma: a comprehensive review. Surgeon. 2014;12(5):290-6. doi: 10.1016/j.surge.2014.02.004. [PubMed: 24650759].

12. Billingsley K. Outcome After Pancreaticoduodenectomy for Periampullary Cancer: An Analysis from the Veterans Affairs National Surgical Quality Improvement Program. J Gastrointestinal Surg. 2003;7(4):484-91. doi:10.1016/s1091-255x(03)00067-2.

13. Choi YM, Cho EH, Lee KY, Ahn SI, Choi SK, Kim SJ, et al. Effect of preoperative biliary drainage on surgical results after pancreaticoduodenectomy in patients with distal common bile duct cancer: focused on the rate of decrease in serum bilirubin. World J Gastroenterol. 2008;14(7):1102-7. doi: 10.3748/wjg.14.1102. [PubMed: 18286694]. [PubMed Central: PMC2689415].

14. van der Gaag NA, de Castro SM, Rauws EA, Bruno MJ, van Eijck CH, Kuipers EJ, et al. Preoperative biliary drainage for periampullary tumors causing obstructive jaundice; DRainage vs. (direct) OPeration (DROP-trial). BMC Surg. 2007;7:3. doi: 10.1186/1471-2482-7-3. [PubMed: 17352805]. [PubMed Central: PMC1828149].

15. Pitt HA, Gomes AS, Lois JF, Mann LL, Deutsch LS, Longmire WJ. Does preoperative percutaneous biliary drainage reduce operative risk or increase hospital cost? Ann Surg. 1985;201(5):545-53. doi: 10.1097/00000658-198505000-00002. [PubMed: 2986562]. [PubMed Central: PMC1250755].

16. Trede M, Schwall G. The complications of pancreatectomy. Ann Surg. 1988;207(1):39-47. doi: 10.1097/00000658-198801000-00009. [PubMed: 3276272]. [PubMed Central: PMC1493257].

17. Armstrong CP, Dixon JM, Taylor TV, Davies GC. Surgical experience of deeply jaundiced patients with bile duct obstruction. Br J Surg. 1984;71(3):234-8. doi: 10.1002/bjs.1800710326. [PubMed: 6607760].

18. van Berge Henegouwen MI, De Wit LT, Van Gulik TM, Obertop H, Gouma DJ. Incidence, risk factors, and treatment of pancreatic leakage after pancreaticoduodenectomy: drainage versus resection of the pancreatic remnant. J Am Coll Surg. 1997;185(1):18-24. doi: 10.1016/s1072-7515(97)00007-0. [PubMed: 9208956].

19. Sauvanet A, Boher JM, Paye F, Bachellier P, Sa Cuhna A, Le Treut YP, et al. Severe Jaundice Increases Early Severe Morbidity and Decreases Long-Term Survival after Pancreaticoduodenectomy for Pancreatic Adenocarcinoma. J Am Coll Surg. 2015;221(2):380-9. doi: 10.1016/j.jamcollsurg.2015.03.058. [PubMed: 26206638].

20. Fang Y, Gurusamy KS, Wang Q, Davidson BR, Lin H, Xie X, et al. Pre-operative biliary drainage for obstructive jaundice. Cochrane Database Syst Rev. 2012;(9). CD005444. doi: 10.1002/14651858.CD005444.pub3. [PubMed: 22972086]. [PubMed Central: PMC4164472]. 